\title{
The effect of whole-body cooling on renal function in post-cardiac arrest patients
}

\author{
Silvia De Rosa ${ }^{1,2,3^{*}}$ (D), Massimo De Cal ${ }^{1,2}$, Michael Joannidis ${ }^{4}$, Gianluca Villa ${ }^{1,5}$, Jose Luis Salas Pacheco ${ }^{6}$, \\ Grazia Maria Virzi ${ }^{1,2}$, Sara Samoni ${ }^{1}$, Fiorella D'ippoliti ${ }^{1,3}$, Stefano Marcante ${ }^{3}$, Federico Visconti ${ }^{3}$, \\ Antonella Lampariello ${ }^{3}$, Marina Zannato ${ }^{3}$, Silvio Marafon ${ }^{3}$, Raffaele Bonato ${ }^{3}$ and Claudio Ronco ${ }^{1,2}$
}

\begin{abstract}
Background: To evaluate the incidence of Acute Kidney Injury (AKI) during therapeutic hypothermia (TH) and rewarming in comatose patients resuscitated from Cardiac Arrest (CA).

Methods: We have performed a pilot study of consecutive comatose patients resuscitated from CA and admitted to our Intensive Care Unit (ICU) from January 2013 to March 2015. The surface cooling devices used were: 1) Arctic Sun $^{\oplus}$ 5000; 2) Blanketro ${ }^{\circledast}$ III. Data obtained at baseline and during TH included: temperature trend and rate, serum creatinine, interleukin 1-beta, interleukin 6 (IL-6), urinary Interleukin-18 (ulL-18), diuretic use, urine output, fluid balance (FB). AKI was defined according to Kidney Diseases Improving Global Outcomes (KDIGO) criteria.

Results: Thirty-six patients were treated with TH out of 46 ICU admissions (78\%). According to KDIGO classification, 21 (58\%) had no evidence of AKI while 15 (41.7\%) presented AKI during TH. In particular, the incidence of AKI was $2.8 \%$ at $24 \mathrm{~h}, 33.33 \%$ at $48 \mathrm{~h}$ and $30.6 \%$ at $72 \mathrm{~h}$ from the onset of cooling. Slower rewarming (above $600 \mathrm{~min}$ ) was associated with with a non-significant lower incidence of AKI and with a non-significant lower levels of IL-6 and IL-18u. Only two patients required renal replacement therapy during TH (7.6\%). Median cumulative FB was 2441 [437-4043] $\mathrm{ml}$ for all patients; 3140 [1421-4347] and 1332 [-131-3772] specifically for AKI and not-AKI patients.

Conclusions: The hypothermia treatment, if not well performed, could be a double-edged sword for kidneys: whereas hypothermia may confer protection by reducing metabolism and oxygen consumption, rapid rewarming could nullify benefits leading to a worsening of kidney function and AKI. Additional clinical studies are needed to determine the optimal rewarming rate and strategy.
\end{abstract}

Keywords: Acute kidney injury, Cardiac arrest, Ischemia reperfusion injury, Hypothermia, Rewarming Injury

\section{Background}

Cardiac Arrest (CA) and resuscitation are an example of a whole-body Ischemia/Reperfusion (I/R) injury characterized by a multi-organ dysfunction and systemic activation of the innate immune system causing a 'sepsis-like syndrome' $[1,2]$. The restoration of spontaneous circulation (ROSC) after prolonged, complete, whole-body ischemia is an unnatural pathophysiological state created by successful cardiopulmonary resuscitation (CPR) [1]. The complex phase of resuscitation which begins when patients regain spontaneous circulation after CA has been defined

\footnotetext{
* Correspondence: derosa.silvia@ymail.com

${ }^{1}$ International Renal Research Institute of Vicenza (IRRIV), Vicenza, Italy

${ }^{2}$ Department of Nephrology, San Bortolo Hospital, Vicenza, Italy

Full list of author information is available at the end of the article
}

by the International Liaison Committee on Resuscitation (ILCOR) as "post-cardiac arrest syndrome" [1]. The ischemia and reperfusion during CA, resuscitation and postresuscitation phases can particularly affect the kidney: I/R injury leads to damage of epithelial cells by increased oxygen radical production [2] and peroxidation of lipids $[3,4]$ but also to interstitial inflammation and interstitial "micro-vasculopathy" that are involved in abnormal repair processes including incomplete repair of tubular cell and fibrosis development [4]. The cross-talk between the kidney and peripheral immune system in humans after whole-body $\mathrm{I} / \mathrm{R}$ injury and the changes over time in the inflammatory response are speculative [5] and aside from cardiogenic shock limited information are available regarding predisposing factors and outcome of acute kidney injury 
(AKI) after CA [6, 7]. Although therapeutic hypothermia $(\mathrm{TH})$, also termed targeted temperature management, is an established intervention (ILCOR/American Heart Associatio) used for neuroprotection $[3,4]$ though recent data challenge the benefit of $\mathrm{TH}$ using target temperature lower than $36{ }^{\circ} \mathrm{C}[8,9]$. The effect of $\mathrm{TH}$ on renal protection is uncertain and poorly investigated.

The purpose of this study was to investigate the effect of TH on the development of AKI and on renal outcomes in comatose patients resuscitated from $\mathrm{CA}$ and treated with surface cooling techniques. We hypothesized that $\mathrm{TH}$ could be a protective strategy against renal I/R injury while the shift from hypo- to normothermia may cause rewarming injury.

\section{Methods}

\section{Study design}

This was a single center observational study. The Institutional Review Board approved the protocol and written informed consent was obtained from the nearest relatives. Data were collected prospectively on 36 patients between January 2013 and March 2015.

\section{Patients selection criteria}

All patients admitted to the emergency department for out-of-hospital CA and treated with $\mathrm{TH}$ in the intensive care unit (ICU) with a standardized protocol [10] were considered eligible for the study. Inclusion criteria were: 18 years or older post-cardiac arrest patients (asystole or pulseless electrical activity or ventricular fibrillation or non-perfusing ventricular tachycardia as initial rhythm) and ST-segment elevation myocardial infarction. Exclusion criteria were: time from ROSC to initiation of cooling $>6 \mathrm{~h}$; body temperature below than $30{ }^{\circ} \mathrm{C}$ on admission; major trauma; severe burns; major surgery less than $72 \mathrm{~h}$; sepsis and septic shock; active bleeding or known pre-existing coagulopathy; intracranial bleeding; pregnancy; aggressive care. Patients were treated either by the Arctic Sun or standard cooling blankets Blanketrol ${ }^{\circ}$ IIIas decided by the treating physician. The time between collapse and start of cooling was calculated based on data provided by the paramedic team.

\section{Patient management}

In all patients, the resuscitation attempt followed the European Resuscitation Council 2010 guidelines for basic and advanced cardiac life support and postresuscitation care [11]. In conjunction with resuscitation procedures, the patient was assessed for study inclusion. ROSC was defined as an organized rhythm and palpable pulse sustained for at least $20 \mathrm{~min}$. In prehospital setting, infusion of ice-cold normal saline, the use of cold packs or the trans-nasal cooling was permitted and it was according to choose of the physician involved in the first aid. If necessary, a coronary angiogram and a percutaneous coronary intervention were performed before the admission to ICU. Once the patient fulfilled the inclusion criteria and in agreement with our protocol, sedation, analgesia, and paralysis were started with: a Propofol bolus of $2 \mathrm{mg} / \mathrm{kg}$, followed by continuous infusion $(0.5-3 \mathrm{mg} / \mathrm{Kg} / \mathrm{h})$ or Midazolam bolus of $0.03-0.04 \mathrm{mg} / \mathrm{kg}$, followed by

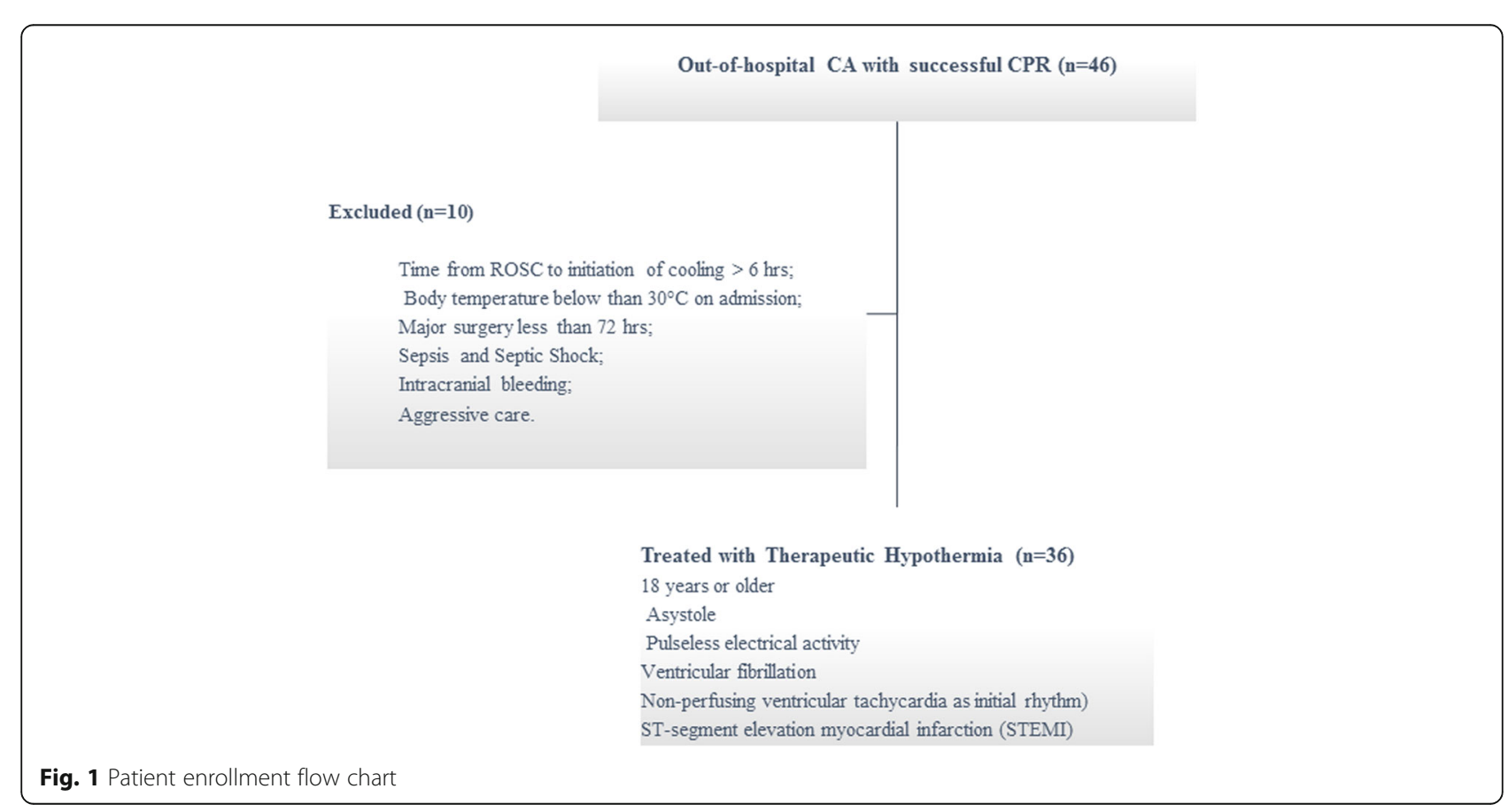


continuous infusion $(0.2 \mathrm{mg} / \mathrm{kg} / \mathrm{hr})$; continuous infusion of Remifentanil $(0.02-0.2 \mathrm{mcg} / \mathrm{kg} / \mathrm{min})$ and of Cisatracurium continuous infusion of $1 \mathrm{mcg} / \mathrm{kg} / \mathrm{min}$. Other treatments such as magnesium, fluids, and vasopressors were left to the discretion of treating physicians. All patients had a bladder temperature probe inserted for a continuous measurement of core temperature, which provides feedback to the cooling devices, freely chosen by the physician involved in the treatment. The cooling devices used were:
1) Blanketrol ${ }^{\bullet}$ III, a cold blanket wrapped around the upper torso. Automatic control mode, designed to limit the magnitude of the difference between the bladder and circulating water temperature (gradient modes), was set with a bladder temperature of $33{ }^{\circ} \mathrm{C}$; If the patient's temperature was lower than the target temperature, the device heated the circulating water to the highest allowable water temperature $\left(42^{\circ} \mathrm{C}\right)$; on the contrary, if the temperature was higher than the target temperature, the device cooled the circulating water to

Table 1 Baseline demographic data, resuscitation details and comorbidities

\begin{tabular}{|c|c|c|c|c|c|c|}
\hline & $\begin{array}{l}\text { Entire Cohort } \\
n=36\end{array}$ & $\begin{array}{l}\text { AKI } \\
n=15\end{array}$ & $\begin{array}{l}\text { No AKI } \\
n=21\end{array}$ & $p$ & $\mathrm{OR}$ & $95 \% \mathrm{Cl}$ \\
\hline Gender & & & & 0.94 & 0.94 & $0.17-4.99$ \\
\hline Male & $29(80.5 \%)$ & $12(80 \%)$ & 17 (81\%) & & & \\
\hline Female & 7 (19.5\%) & $3(20 \%)$ & $4(19 \%)$ & & & \\
\hline Age (yrs) & $60.5[53-72.5]$ & $60[52-77]$ & $63[54-67]$ & 0.5 & 1.02 & $0.96-1.07$ \\
\hline BMI & $26[23-28.7]$ & $27.6[23.2-29.4]$ & $24.7[23-27.8]$ & 0.18 & 1.13 & $0.94-1.35$ \\
\hline SOFA score & $9[8-11]$ & $10[8-11]$ & $9[8-11]$ & 0.79 & 105 & $0.75-1.46$ \\
\hline APACHE II score & $24[21-26]$ & 26 [22-29] & $24[21-24]$ & 0.04 & 1.25 & $1.02-1.55$ \\
\hline Presenting Cardiac Rhythm & & & & 0.95 & 1.05 & $0.20-5.43$ \\
\hline VFNT & $29(81 \%)$ & $12(80 \%)$ & 17 (81\%) & & & \\
\hline PEA/Asystolia & $7(19 \%)$ & $3(20 \%)$ & $4(19 \%)$ & & & \\
\hline Prehospital cooling & $11(30.5 \%)$ & $6(40 \%)$ & $5(23.8 \%)$ & 0.12 & 0.35 & $0.09-1.30$ \\
\hline Re-arrest after ROSC & & & & 0.68 & 0.84 & 0.371 .91 \\
\hline Shockable & $11(30.5 \%)$ & $6(40 \%)$ & $5(23.8 \%)$ & & & \\
\hline No-Shockable & $1(2.8 \%)$ & $0(0 \%)$ & $1(4.8 \%)$ & & & \\
\hline None re-arrest & $24(66.6 \%)$ & $9(60 \%)$ & 15 (75\%) & & & \\
\hline ECM & & & & 0.24 & 1.58 & $0.74-3.39$ \\
\hline Trained & $11(30.6 \%)$ & $3(20 \%)$ & $8(38.1 \%)$ & & & \\
\hline Untrained & $12(33.3 \%)$ & $5(33.3 \%)$ & 7 (33.3\%) & & & \\
\hline Lukas & $5(13.9 \%)$ & $3(20 \%)$ & $2(9.5 \%)$ & & & \\
\hline Non performed & $8(22.2 \%)$ & $4(26.7 \%)$ & $4(19 \%)$ & & & \\
\hline Total Number Of Shock & $3[1.2-7]$ & $3[2-4]$ & $3[1-7]$ & 0.39 & 086 & $0.61-1.21$ \\
\hline Total Adrenaline Given (mg) & $1[0-3.75]$ & $0[0-3]$ & $1[0-4]$ & 0.64 & 0.94 & $0.71-1.23$ \\
\hline Total Amiodarone Given (mg) & $0[0-300]$ & $0[0-0]$ & $0[0-300]$ & - & - & - \\
\hline \multicolumn{7}{|l|}{ Comorbidities } \\
\hline Hypertension & $14(22.2 \%)$ & $8(38.1 \%)$ & $6(28.6 \%)$ & 0.14 & 0.35 & $0.09-1.40$ \\
\hline Previous Kidney Disease & $0(0 \%)$ & $0(0 \%)$ & $0(0 \%)$ & - & - & - \\
\hline Previous Cardiac Surgery & $2(5.5 \%)$ & $2(13.3 \%)$ & $0(0 \%)$ & - & - & - \\
\hline Coronary Artery Disease & $24(66.6 \%)$ & $11(73.3 \%)$ & $13(61.9 \%)$ & 0.48 & 0.59 & $0.14-2.50$ \\
\hline Insulin Required Diabetes & $8(22 \%)$ & 7 (46.7\%) & 1 (4.7\%) & 0.01 & 0.05 & $0.005-0.48$ \\
\hline COPD & $3(8.4 \%)$ & $3(20 \%)$ & $0(0 \%)$ & - & - & - \\
\hline
\end{tabular}

All quantitative variables are presented as median value [IQR], while quantitative data as total number (\%). The differences between AKI and No-AKI patients has been tested through multivariate analysis

Abbreviations: BMI Body Mass Index, SOFA Sequential Organ Failure Assessment, APACHE Acute Physiology and Chronic Health Evaluation, VF Ventricular Fibrillation, VT Ventricular Tachycardia, PEA Pulseless Electrical Activity, ROSC Restoration Of Spontaneous Circulation, ECM External Cardiac Massage, COPD Chronic Obstructive Pulmonary Disease, AKI Acute Kidney Injury 
the lowest allowable water temperature $\left(4{ }^{\circ} \mathrm{C}\right)$ until the achieving the body target temperature. The circulation of the water without heating or cooling characterizes the reach of the target temperature.

2) Arctic $\operatorname{Sun}^{\oplus} 5000$, the cooling pads applied on the back, chest and thighs. Automatic mode was set to a target temperature of $33{ }^{\circ} \mathrm{C}$, and the maximum cooling rate was used. The decision of the cooling device was performed by treating physician based on his preference. Target temperature was achieved and maintained for $24 \mathrm{~h}$. At the end of the maintenance phase, rewarming phase started with a target temperature of $36^{\circ} \mathrm{C}$ and with a rewarming rate between $0.25-0.5^{\circ} \mathrm{C}$ per hour. Once the patient's temperature reached $36^{\circ} \mathrm{C}$, the device was turned off.

\section{Data collection and blood sampling}

Demographic variables and pre-hospital data were collected prospectively for all patients at the admission utilizing the Utstein criteria. Hemodynamic parameters and temperature were measured continuously. Data obtained on admission and 6, 24, 48 and $72 \mathrm{~h}$ included: temperature trend and rate, serum creatinine $(\mathrm{sCr})$, interleukin 6 (IL-6), interleukin 1-beta (IL-1beta), urinary interleukin -18 (uIL-18), urine output, fluid balance.

AKI was defined according to Kidney Diseases Improving Global Outcomes (KDIGO) criteria [12, 13]. Estimated Glomerular Filtration Rate and urinary output criteria were not used for AKI diagnosis and staging in this study. Baseline $\mathrm{sCr}$ was calculated using the Modification of Diet in Renal Disease (MDRD) equation (back-estimation). In particular, in absence of previous values, the baseline creatinine has been calculated as follow: GFR(Glomerular Filtration Rate $)=\left(75 /\left[186 \times\left(\right.\right.\right.$ age $\left.^{-0.203}\right) \times(0.742$ if female $) \times(1.21$ if black) $])^{-0.887}$ ). For each time point, $\mathrm{sCr}$ considered for AKI diagnosis was corrected for fluid balance according to recent evidence [14]. The Sequential Organ Failure
Assessment (SOFA) score was calculated using standard methods. Quantitative determination of UIL-18 was performed by Human Instant ELISA kit (eBioscience, San Diego, CA, USA). Cytokines determinations were performed according to manufacturer's protocol and instructions. Optical density was read by using a VICTORX4 Multilabel Plate Reader (PerkinElmer Life Sciences, Waltham, MA, USA) at $450 \mathrm{~nm}$. The concentration values for these molecules were calculated from standard curves, according to the manufacturer's protocols. All tests were performed in triplicate.

\section{Outcomes}

The primary outcome was the development of AKI during all treatment period in patients treated with either one of the two cooling devices. The secondary outcomes were: the evaluation of association between duration of each phase of TH (i.e. cooling, hypothermia, rewarming) and $\mathrm{AKI}$; the variation of $\mathrm{sCr}$, urine output, fluid balance and serum cytokine during $\mathrm{TH}$; the effects of rewarming phase on development of AKI. The outcomes were assessed by study personnel who were aware of the type of external cooling assigned for the subject.

\section{Statistical analysis}

The Shapiro-Wilk test was used to test the data for normality. The differences between AKI and not-AKI patients were tested using Mann-Whitney-Wilcoxon for continuous variables, according to the not-normal distribution of data, and presented as median [I-III interquartile]. Categorical variables were analyzed using the chi-square test and given as a percentage. Differences between AKI and not-AKI have also been evaluated through univariate and multivariate analysis; results are presented in tables as $p$ values, Odds ratio (OR) and 95\% confidence interval (95\% CI). A $p$ value less than 0.05 was considered for statistical

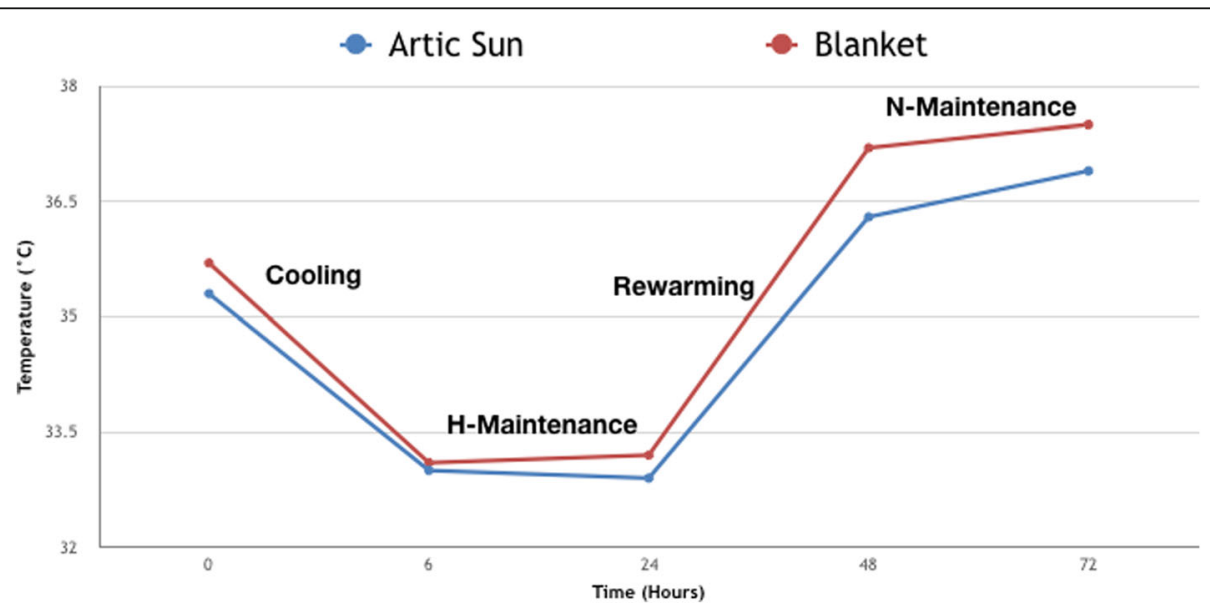

Fig. 2 Bladder temperature trend in the Artic Sun Group and Blanket Group within the first $72 \mathrm{~h}$. Data are given as median values 
significance. Data were analyzed using STATA 12 software (STATA corp, 490, Lakeway Drive College Station, 77845, Texas, US).

\section{Results}

\section{Baseline demographics}

From January 2013 till March 2015, 36 patients with successful CPR were treated by $\mathrm{TH}$ out of $46 \mathrm{ICU}$ admissions for CA (78\%) to the Department of Anesthesia and Intensive Care Medicine, San Bortolo Hospital (Fig. 1) and followed for the development of AKI during ICU stay (Table 1). Ten (28\%) patients were treated with Blanketroll III (Blanket Group), and twenty-six (72\%) patients were treated with the Arctic Sun Cooling Machine (Artic Sun Group).
Temperature trend and duration of each treatment phase At the initiation of cooling, the temperature dropped from a median pre-treatment temperature of 35.6 [34.7-36] ${ }^{\circ} \mathrm{C}$ for Artic Sun Group and 35.7 [35.1-36.1] ${ }^{\circ} \mathrm{C}$ for Blanket Group, to respectively a median plateau value of $33{ }^{\circ} \mathrm{C}$ and $33.1{ }^{\circ} \mathrm{C}$. At $6 \mathrm{~h}$, the target temperature of $33^{\circ} \mathrm{C}$ was reached in both groups.

At $24 \mathrm{~h}$, the median temperature reached was 32.9 [32.7-33] ${ }^{\circ} \mathrm{C}$ in the Artic Sun Group and 33.3 [32.933.5 ${ }^{\circ} \mathrm{C}$ in the Blanket Group. The median temperature kept during the rewarming period was 36.5 [36-36.7] ${ }^{\circ} \mathrm{C}$ in the Artic Sun Group and $37.5[36.8-37.7]{ }^{\circ} \mathrm{C}$ in the other Group, respectively. The median temperature kept during the normothermic period was $36.7[36.2-37]{ }^{\circ} \mathrm{C}$ in the Artic Sun and 37.4 [37.2-37.8] ${ }^{\circ} \mathrm{C}$ in the other Group (Fig. 2). The duration of each phase and the time

Table 2 Renal outcomes

\begin{tabular}{|c|c|c|c|c|c|c|}
\hline & $\begin{array}{l}\text { Entire Cohort } \\
n=36\end{array}$ & $\begin{array}{l}\text { AKI } \\
n=15\end{array}$ & $\begin{array}{l}\text { No AKI } \\
n=21\end{array}$ & $p$ & OR & $95 \% \mathrm{Cl}$ \\
\hline LVEF $<35$ & $14(38 \%)$ & 7 (46.7\%) & 7 (33.3\%) & 0.37 & 0.53 & $0.13-2.14$ \\
\hline \multicolumn{7}{|l|}{ VIS } \\
\hline Admission & $0[0-5]$ & $0[0-0]$ & $0[0-0]$ & 0.75 & 1.02 & $0.89-1.16$ \\
\hline $6 \mathrm{~h}$ & $5.7[0-16]$ & $3.7[0-8.9]$ & $9.8[0-16.6]$ & 0.36 & 0.95 & $0.85-1.05$ \\
\hline $24 \mathrm{~h}$ & $5.5[2.1-11]$ & $4[2.4-6.5]$ & 7 [2-12.3] & 0.27 & 0.91 & $0.76-1.08$ \\
\hline $48 \mathrm{~h}$ & 2 [0-8.9] & $3.9[0-11]$ & $2.1[0-7]$ & 0.48 & 0.96 & $0.85-1.07$ \\
\hline $72 \mathrm{~h}$ & $0[0-5.7]$ & $2.3[0-6.8]$ & $0[0-5]$ & 0.15 & 1.25 & $0.92-1.72$ \\
\hline \multicolumn{7}{|l|}{ MAP } \\
\hline Admission & 86 [70-109] & 84 [67-112] & 89 [71-109] & 0.26 & 0.97 & $0.93-1.02$ \\
\hline $6 \mathrm{~h}$ & 84 [70-100] & 82 [70-100] & 85 [69-100] & 0.56 & 1.02 & $0.95-1.09$ \\
\hline $24 \mathrm{~h}$ & 83 [71-90] & 79 [68-86] & 84 [72-92] & 0.59 & 0.98 & $0.91-105$ \\
\hline $48 \mathrm{~h}$ & 82 [69-94] & 88 [77-95] & 78 [68-89] & 0.37 & 1.03 & $0.97-1.09$ \\
\hline $72 \mathrm{~h}$ & 84 [71-95] & 74 [66-90] & 92 [82-107] & 0.06 & 0.95 & $0.89-1.00$ \\
\hline \multicolumn{7}{|l|}{ Fluid Balance } \\
\hline $24 \mathrm{~h}$ & $333[-434-1280]$ & 448 [95-1250] & $5[-703-1477]$ & 0.53 & 0.99 & $0.99-1.00$ \\
\hline $48 \mathrm{~h}$ & 1522 [488-2236] & 1290 [344-2621] & 1592 [587-2099] & 0.56 & 0.99 & $0.99-1.00$ \\
\hline $72 \mathrm{~h}$ & $621[-389-1749]$ & 1155 [129-2168] & $393[-1567-1475]$ & 0.67 & 0.99 & $0.99-1.00$ \\
\hline Cumulative & 2441 [437-4043] & 314 [1421-4347] & $1332[-131-3772]$ & 0.54 & 0.99 & $0.99-1.00$ \\
\hline \multicolumn{7}{|l|}{ Urinary Output } \\
\hline $24 \mathrm{~h}$ & 2242 [1403-2844] & 1890 [1100-2853] & 2245 [1720-2820] & 0.40 & 0.99 & $0.99-1.00$ \\
\hline $48 \mathrm{~h}$ & 2877 [2362-3552] & 2810 [2280-3400] & 2990 [2400-3620] & 0.19 & 1.00 & $0.99-1.00$ \\
\hline $72 \mathrm{~h}$ & 3185 [2538-4060] & 3010 [2370-4470] & 3627 [2605-4040] & 0.27 & 0.99 & $0.99-1.00$ \\
\hline Ventilation days & $8[4-12.7]$ & $6[3-11]$ & $8[4-14]$ & 0.94 & 0.99 & $0.93-1.07$ \\
\hline ICU days & $9[4.5-12.5]$ & 8 [4-12] & $9[4.5-14]$ & 0.99 & 1.00 & $0.93-1.07$ \\
\hline ICU mortality & $23(63.9 \%)$ & $9(60 \%)$ & $14(66.7 \%)$ & 0.68 & 0.75 & $0.19-2.96$ \\
\hline Hospital mortality & $25(69.4 \%)$ & $10(66.7 \%)$ & $15(71.4 \%)$ & 0.99 & 1 & $0.93-1.08$ \\
\hline 90-days mortality & $25(69.4 \%)$ & $10(66.7 \%)$ & 15 (71.4\%) & 0.99 & 1 & $0.93-1.08$ \\
\hline
\end{tabular}

Continuous variables are expressed as median [IQR], qualitative data as number (\%)

Abbreviation: AKI acute kidney injury, ICU intensive care unit, LVEF Left ventricular ejection fraction, MAP mean arterial pressure, RRT renal replacement therapy, VIS vasoactive inotropic score 


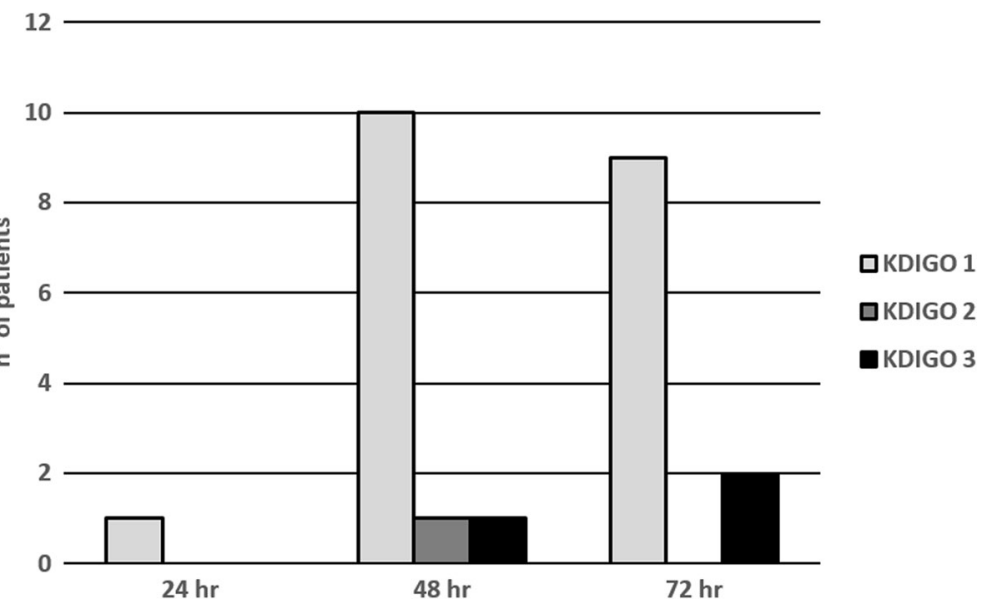

Fig. 3 Incidence of AKI at different time points. From $24 \mathrm{~h}$ until $48 \mathrm{~h}$ there is an increase of AKI patients at KDIGO stage 1 and from $48 \mathrm{~h}$ until $72 \mathrm{~h}$ there an increase of patients at KDIGO stage 3

to fever, defined as the temperature above a threshold of $37.5^{\circ} \mathrm{C}$, is expressed in Table 2 .

\section{AKI development during $\mathrm{TH}$ treatment}

According to KDIGO classification, among all 36 patients, 21(58\%) had no evidence of AKI while 15(41.7\%) had AKI during TH. The incidence of AKI for each time point is reported in Fig. 3.

In all population, the median time for rewarming was 600 [480-720] min. Although there is no statistically significant difference, patients with AKI had a slightly increase in rewarming time compared to patients without AKI, respectively 540 [480-720] min vs 630 [480-720] $\min (p=0.13)$ (Table 3).

$s \mathrm{Cr}$, fluid balance, urine output, diuretic use and need of renal replacement therapy (RRT) during TH treatment Considering overall population, median values of $\mathrm{sCr}$ based on MDRD formula was 1.06 [1.02-1.09] $\mathrm{mg} / \mathrm{dl}$ ) while $\mathrm{sCr}$ at admission was 1.12 [0.94-1.22] $\mathrm{mg} / \mathrm{dl}$. These values were: 0.82 [0.63-1.07], 1.04 [0.77-1.32], 1.06 [0.79$1.42 \mathrm{mg} / \mathrm{dl}$ respectively at $24 \mathrm{~h}, 48 \mathrm{~h}, 72 \mathrm{~h}$. sCr between patients with AKI and no AKI is shown in Fig. 4.
Urine output increased from $24 \mathrm{~h}$ until to $72 \mathrm{~h}$. The average daily dose of frusemide was 20 [0-20] mg. N differences have been observed for urinary output between patients treated with or without diuretics at $24 \mathrm{~h}(p=$ $0.74), 48 \mathrm{~h}(p=0.35)$ and $72 \mathrm{~h}(p=0.23)$.

In overall population, the median fluid balance from $24 \mathrm{~h}$ to $72 \mathrm{~h}$ was +2441 [432-4044] ml. Only two patients required RRT during the treatment (7.6\%) (Table 2).

\section{Cytokines concentration during the treatment period}

For each time point, the plasmatic concentration of IL-6 and IL-1beta and the urinary concentration of UIL-18 have been described for overall population and for AKI and no AKI patients in Table 4. Figure 5 shows cytokines levels at different timepoint in AKI and not-AKI patients with slow rewarming (Panel A) and with rapid rewarming (Panel B).

\section{Discussion}

To the best of our knowledge, this is the first study suggesting that the rewarming phase after $\mathrm{TH}$ applied to post-CA patients may have an impact on the development of AKI. During the TH period, among all 36 patients, 21 (58\%) had no evidence of AKI according to KDIGO classification. AKI is a common occurrence, in particular from

Table 3 Time duration of each treatment phase

\begin{tabular}{|c|c|c|c|c|c|c|}
\hline & $\begin{array}{l}\text { Entire Cohort } \\
n=36\end{array}$ & $\begin{array}{l}\text { AKI } \\
n=15\end{array}$ & $\begin{array}{l}\text { No AKI } \\
n=21\end{array}$ & $p$ & OR & $95 \% \mathrm{Cl}$ \\
\hline Time from CA to $33^{\circ} \mathrm{C}$ & $280.5[240-385]$ & 256.5 [216-325] & 330.5 [254-390] & 0.09 & 0.96 & $0.92-1.00$ \\
\hline Time from $\mathrm{TH}$ induction to $33^{\circ} \mathrm{C}$ & 184.5 [120-248] & 180 [120-210] & 192 [120-252] & 0.09 & 1.04 & $0.99-109$ \\
\hline Time of $\mathrm{TH}$ duration & $1440[1440-1557]$ & 1440 [1440-1620] & $1440[1440-1500]$ & 0.33 & 0.99 & $0.97-1.00$ \\
\hline Time from $33{ }^{\circ} \mathrm{C}$ to $36^{\circ} \mathrm{C}$ & $600[480-720]$ & 540 [480-720] & $630[480-720]$ & 0.13 & 0.99 & $0.99-1.00$ \\
\hline Time from $36{ }^{\circ} \mathrm{C}$ to fever & 1380 [487-3180] & $2880[300-4320]$ & 1260 [495-2880] & 0.31 & 1.00 & $0.99-100$ \\
\hline
\end{tabular}

Median duration of treatment phases for all patients and specifically for AKI and no-AKI patients. All periods of time are expressed in minutes Abbreviations: CA Cardiac Arrest, TH Therapeutic Hypothermia, AKI Acute Kidney Injury 


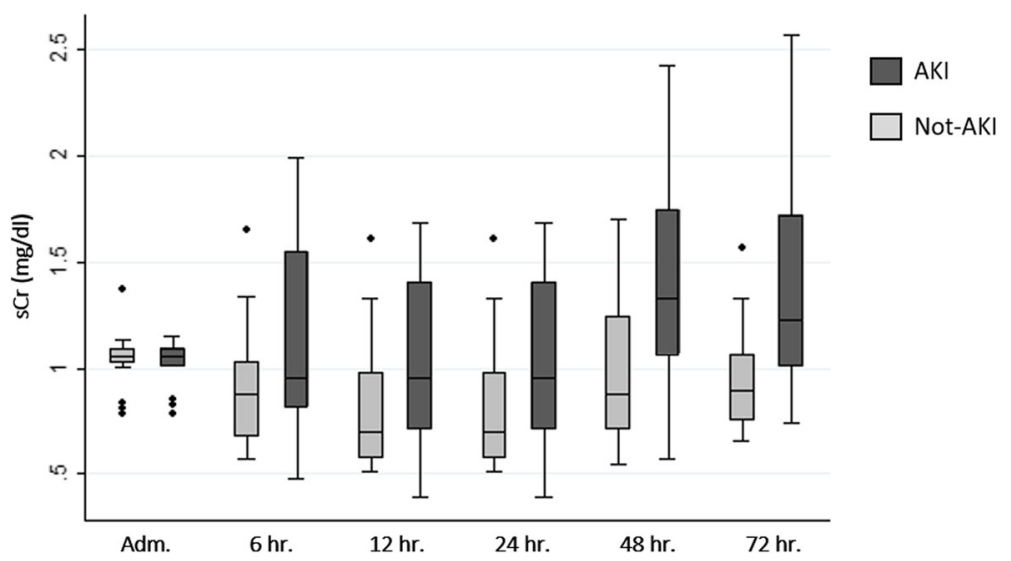

Fig. $4 \mathrm{~s} C r$ in patients with and without AKI at different time points. $\mathrm{sCr}$ levels progressively increases in AKI patients from $24 \mathrm{~h}$ until $72 \mathrm{~h}$ conversely to non-AKI patients

out-of-hospital-CA patients. Indeed, post-cardiac arrest is characterized by a whole-body ischemia followed by reperfusion with activation of a systemic inflammatory response and release of injury products into the circulation $[5,6]$ responsible of additive stimuli for ischemic injury [15]. Following resuscitation from spontaneous CA, AKI is a common complication with increased mortality risk, dialysis requirement and prolonged hospital stay [7, 16, 17]. An intriguing field of research shows the capability of a decrease in whole-body temperature to limit the ischemic injuries. Although TH has been used from 1950s to protect the brain against a global ischemia after $\mathrm{CA}$, there is scant data on the potential benefit of this strategy on kidney endpoints $[18,19]$. Experimental studies

Table 4 Cytokines trend in the two different groups of patients

\begin{tabular}{|c|c|c|c|c|c|c|}
\hline & $\begin{array}{l}\text { Entire Cohort } \\
n=36\end{array}$ & $\begin{array}{l}\text { AKI } \\
n=15\end{array}$ & $\begin{array}{l}\text { No AKI } \\
n=21\end{array}$ & $p$ & OR & $95 \% \mathrm{Cl}$ \\
\hline \multicolumn{7}{|l|}{ IL-6 } \\
\hline Admission & 79.05 [31.34-113.52] & 82.79 [37.12-93.31] & 62.32 [28.66-139.95] & 0.28 & 0.99 & $0.98-1.00$ \\
\hline $6 \mathrm{~h}$ & 56.9 [22.52-165.45] & $36.50[12.1-60.18]$ & 64.96 [22.52-188.4] & 0.62 & 0.99 & $0.99-1.00$ \\
\hline $12 \mathrm{~h}$ & 53.58 [39.04-121.25] & 45.17 [28.91-53.76] & 63.88 [47.79-177.5] & 0.38 & 0.99 & $0.99-1.00$ \\
\hline $24 \mathrm{~h}$ & 46.75 [22.36-94.37] & $46.46[21.21-64.29]$ & 46.75 [22.69-98.61] & 0.80 & 0.99 & $0.98-1.00$ \\
\hline $48 \mathrm{~h}$ & 44.38 [26.45-78.45] & 57.83 [31.93-74.84] & 40.63 [24.33-82.06] & 0.69 & 1.00 & $0.99-1.01$ \\
\hline $72 \mathrm{~h}$ & 48.89 [27.85-73.38] & 43.47 [27.77-89.84] & $48.91[27.93-67.1]$ & 0.24 & 1.00 & $0.99-1.02$ \\
\hline \multicolumn{7}{|l|}{ IL-1beta } \\
\hline Admission & 13.27 [11.3-20.41] & 11.87 [10.87-15.2] & $14.91[12.3-23.22]$ & 0.28 & 0.96 & $0.90-1.03$ \\
\hline $6 \mathrm{~h}$ & 13.04 [9.93-16.48] & 10.76 [9.58-13.98] & 14.65 [11.52-20.43] & 0.29 & 0.97 & $0.91-1.03$ \\
\hline $12 \mathrm{~h}$ & 13.13 [11.71-16.54] & 12.94 [10.52-20.33] & 13.13 [12.34-14.92] & 0.74 & 1.01 & $0.94-1.08$ \\
\hline $24 \mathrm{~h}$ & 14.15 [11.85-21.92] & 14.14 [11.43-18.76] & 14.79 [11.96-21.92] & 0.54 & 0.98 & $0.93-1.04$ \\
\hline $48 \mathrm{~h}$ & 13.58 [11.62-17.52] & 15.93 [11.21-19.01] & 13.55 [11.62-16.63] & 0.73 & 0.99 & $0.93-1.05$ \\
\hline $72 \mathrm{~h}$ & 14.21 [11.64-22.27] & 14.20 [10.56-17.22] & 14.31 [11.64-49.43] & 0.51 & 0.98 & $0.94-1.03$ \\
\hline \multicolumn{7}{|l|}{ ulL-18 } \\
\hline Admission & 370.13 [319.63-740.5] & 559.35 [369.76-997.36] & 361.64 [309.94-412.06] & 0.29 & 1.00 & $0.99-1.00$ \\
\hline $12 \mathrm{~h}$ & 325.7 [299.6-375.5] & 317.97 [262.60-345.89] & $329.16[303.16-375.9]$ & 0.50 & 0.99 & $0.99-1.00$ \\
\hline $24 \mathrm{~h}$ & 330.16 [280.93-365.5] & 327.42 [288.01-361.53] & 330.16 [219.25-373] & 0.91 & 0.99 & $0.99-1.00$ \\
\hline $48 \mathrm{~h}$ & 335.92 [289.68-393.47] & $355.5[301.5-566.52]$ & 331.24 [277.84-365.5] & 0.29 & 1.00 & $0.99-1.00$ \\
\hline $72 \mathrm{~h}$ & 331.96 [207-439.37] & 366.61 [331.92-845.5] & 323.71 [130.05-405.5] & 0.16 & 1.00 & $0.99-1.00$ \\
\hline
\end{tabular}

All cytokines concentrations are expressed in $\mathrm{pg} / \mathrm{ml}$ and presented as median value [IQR]. The difference in cytokines concentrations at each time points has been tested again the AKI development through multivariate analysis

Abbreviations: IL-6 Interleukin 6, IL-1beta Interleukin 1beta, ulL-18 urinary Interleukin 18, AKI, Acute Kidney Injury 

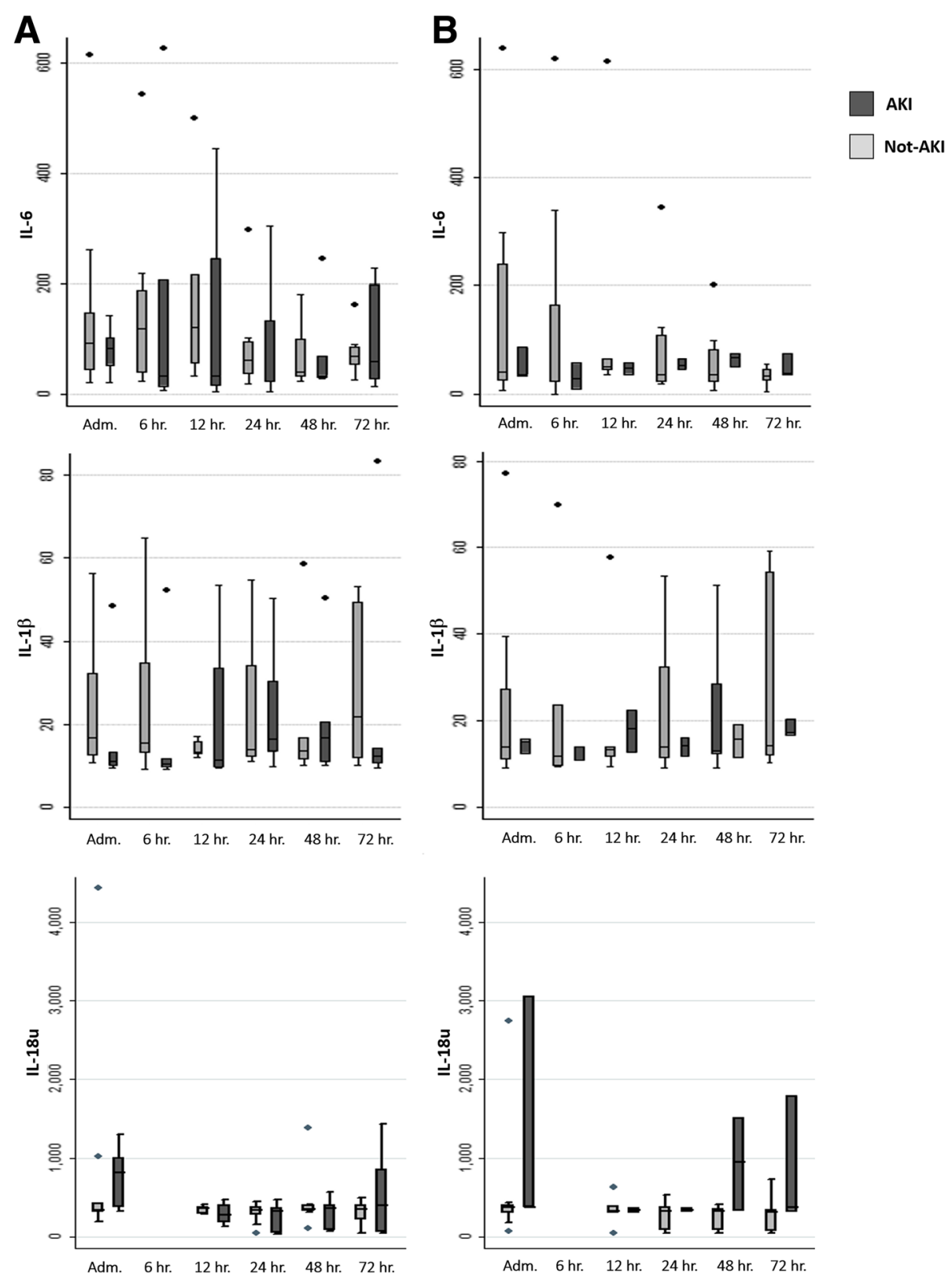

Fig. 5 Cytokines in patients with rewarming time below and above 600 min. 5 shows cytokines levels at different timepoint in AKI and not-AKI patients with slow rewarming (Panel a) and with rapid rewarming (Panel b)

investigated the effect of body temperature on renal susceptibility. On the basis of renal ischemic preservation by using low body temperature hypothermia, Pelkey et al. demonstrated that minimal temperature changes during renal ischemia alter functional and morphologic outcome [20]. These findings in literature showed that in animals hypothermia is able to reduce the risk of renal failure after renal I/R injury [21, 22]. Renal function is eventually depressed during hypothermia owing to a fall in systemic blood pressure and the effect of hypothermia on organ metabolism itself. As renal blood flow progressively decreases, renal vascular resistance rises, promoting a further decrease in renal flow and a subsequent decrease in glomerular filtration. Increased blood viscosity and vasoconstriction were both responsible for this reduction of flow. In the setting of $\mathrm{TH}$, this effect is maintained for $24 \mathrm{~h}$. In this hypothermic phase, from admission to $24 \mathrm{~h}$, there is a decrease of $\mathrm{sCr}$ probably due to decrease in muscle metabolism. Clinical practice is based on $\mathrm{sCr}$ measurements to monitor renal function and classify AKI. For this reason, we used a validated criteria to define and classified AKI: KDIGO. It is presumed 
that $\mathrm{TH}$ increases urine output particularly in the induction phase, this phenomenon is called cold-induced diuresis [23]. For this reason, we decide to not consider urinary output criteria for diagnosis of AKI. Our results suggested that in the rewarming phase, which started after $24 \mathrm{~h}$, there is a slight increase of $\mathrm{sCr}$ associated with an increase in urine output that did not correlate with diuretic dose. Rewarming is a delicate phase of therapeutic hypothermia. Similar to the brain [24], the rewarming phase seems to be very important for the kidney and we strongly believe that could be dangerous if it is not performed slowly and with adequate time duration. Our results showed that with a rewarming time more than 600 min the risk of AKI is decreased. However, it does not mean that longer rewarming times exclude any risk of AKI. Rewarming of the patient is begun $24 \mathrm{~h}$ after the initiation of cooling. The literature recommends rewarming slowly at a temperature of $0.3-0.5{ }^{\circ} \mathrm{C}$ every hour. It means that rewarming will take approximately $8 \mathrm{~h}$ [25]. Differences in the time of rewarming could impact microinflammation and AKI risk.

In our study, patients who did not develop AKI had median rewarming time of $630 \mathrm{~min}(10.5 \mathrm{~h})$ whereas those who did develop AKI had a median time of 540 $(9 \mathrm{~h})$. Rewarming is a delicate phase of $\mathrm{TH}$. Adverse consequences of rewarming on the whole body may seriously limit the protective effects of hypothermia, leading to secondary injury. In literature, previous studies showed that the rise in body temperature accompanies a vasodilation causing a rewarming shock and then careful fluid monitoring during rewarming is crucial [26]. Probably, controlled rewarming of $0.15{ }^{\circ} \mathrm{C}$ per hour should be recommended [27] Our data support this recommendation showing less AKI with rewarming time $>600 \mathrm{~min}$ which would translate to a rewarming rate of less than $0,4{ }^{\circ} \mathrm{C} / \mathrm{h}$. It should be considered that in patients with severe oliguria or anuria despite volume resuscitation, RRT should be started before rewarming to avoid hyperkalemia or metabolic acidosis due to transcellular electrolyte shifts associated with this phase [28]. Hypothermia suppresses ischemia-induced inflammatory reactions and release of pro-inflammatory cytokines [29]. In our study, we assessed inflammatory response dosing IL-6, IL-1beta and IL-18 and results supported the evidence. In addition, uIL-18, a 22 $\mathrm{KDa}$ pro-inflammatory cytokine, produced by immune cells, macrophages and proximal tubular cells, has a role in inflammatory processes that exacerbate renal injury during the extension phase of AKI [30,31]. This cytokine is an early biomarker for AKI in a variety of clinical scenarios indicating the activation of inflammation in kidney [32-34]. Our results showed that with a rewarming time less than $600 \mathrm{~min}$, there is a more increase in concentration respect to those with a slower rewarming (above $600 \mathrm{~min}$ ) supporting the hypothesis that rapid rewarming is associated with increase risk of AKI (Table 4). The study has some limitations. First, this is a single center trial with only a relative small number of patients included. Secondly, the patients were assigned to two different cooling methods in a nonrandomized fashion. Thus, a bias introduced by the cooling method cannot be excluded. Our results, suggest possible harm by an insufficiently controlled and or too short rewarming period. As feasibility study, there was not a comparison with a normothermic control group. The study is too small to make conclusions about outcomes, although the results are hypothesis generating.

\section{Conclusions}

The hypothermia treatment, if not well performed, could be a double-edged sword for kidneys: whereas hypothermia may confer protection by reducing metabolism and oxygen consumption, rapid rewarming could nullify benefits leading to a worsening of kidney function and AKI. Additional clinical studies are needed to determine the optimal rewarming rate and strategy.

\section{Key messages}

- In our prospective study, a rewarming time of more than $600 \mathrm{~min}$ is associated to a decrease of the risk of AKI;

- The uIL-18 levels has a role in inflammatory processes that exacerbate renal injury during the extension phase of AKI. During rewarming time less than 600 min, there is a more increase in concentration respect to those with a slower rewarming (above $600 \mathrm{~min}$ ) supporting the hypothesis that rapid rewarming is associated with increase risk of AKI.

- Whereas hypothermia may confer protection by reducing metabolism and oxygen consumption, rapid rewarming could nullify benefits leading to a worsening of kidney function and AKI.

\section{Abbreviations}

AKI: Acute Kidney Injury; CA: Cardiac Arrest; CPR: Cardiopulmonary Resuscitatione; GFR: estimated Glomerular Filtration Rate; I/R: Ischemia/Reperfusion; ICU: Intensive Care Unit; IL-1 beta: Interleukin 1 beta; IL-6: Interleukin 6; ILCOR: International Liaison Committee on Resuscitation; KDIGO: Kidney Diseases Improving Global Outcomes; MDRD: Modification of Diet in Renal Disease; ROSC: Restoration of spontaneous circulations; Cr: Serum Creatinine; SOFA: Sequential Organ Failure Assessment; STEMI: ST-Segment Elevation Myocardial Infarction; TH: Therapeutic Hypothermiau; IL18: Urinary Interleukin 18

\section{Acknowledgements}

We thank all investigators, doctors and nurses of the participating Intensive Care Unit and AARVI onlus for their invaluable collaboration.

\section{Ethical approval and consent to participate}

The approval, as clinical protocol, was given from the Institutional Review Boards of San Bortolo Hospital in Vicenza. The requirement to obtain informed consent was waived because therapeutic hypothermia was performed as routine treatment of CA patients after ROSC. This study was performed according to the ethical principles of the Declaration of Helsinki. 


\section{Funding}

Not applicable

\section{Availability of data and materials}

The datasets used and/or analysed during the current study are available from the corresponding author on reasonable request.

\section{Authors' contributions}

All authors have contributed to this manuscript and approved this version for submission. SDR, MDC, CR and MJ designed the study. SDR,MDC, SS, SM, $M G V, F V, A L, R B$ and $M Z$ contributed in recruitment of patients and data collection. GV, SDR, MJ and JLSP processing and analysis of results. SDR, GV, $M J, S S, F D, S M, M G V$ and MDC wrote the first draft of the manuscript. RB and CR helped to revise the manuscript. All coauthors participated in subsequent revisions of the manuscript. All authors critically reviewed the manuscript.

\section{Consent for publication}

Not applicable

\section{Competing interests}

The authors declare that they have no competing interests.

\section{Publisher's Note}

Springer Nature remains neutral with regard to jurisdictional claims in published maps and institutional affiliations.

\begin{abstract}
Author details
${ }^{1}$ International Renal Research Institute of Vicenza (IRRIV), Vicenza, Italy. ${ }^{2}$ Department of Nephrology, San Bortolo Hospital, Vicenza, Italy. ${ }^{3}$ Department of Anesthesia and Intensive Care, San Bortolo Hospital, Viale Rodolfi 37, 36100 Vicenza, Italy. ${ }^{4}$ Division of Intensive Care and Emergency Medicine, Department of Internal Medicine, Medical University Innsbruck, Innsbruck, Austria. ${ }^{5}$ Department of Health Science, Section of Anaesthesiology and Intensive Care, University of Florence, Florence, Italy. Instituto Nacional de Cardiología-lgnacio Chávez, Mexico City, Mexico.
\end{abstract}

Received: 7 February 2017 Accepted: 7 December 2017 Published online: 29 December 2017

\section{References}

1. Neumar RW, Nolan JP, Adrie C, Aibiki M, Berg RA, Bottiger BW, Callaway C, Clark RS, Geocadin RG, Jauch EC, et al. Post-cardiac arrest syndrome: epidemiology, pathophysiology, treatment, and prognostication. A consensus statement from the international liaison committee on resuscitation (American Heart Association, Australian and New Zealand council on resuscitation, European resuscitation council, Heart and Stroke Foundation of Canada, InterAmerican Heart Foundation, resuscitation Council of Asia, and the resuscitation Council of Southern Africa); the American Heart Association emergency cardiovascular care committee; the council on cardiovascular surgery and anesthesia; the council on cardiopulmonary, perioperative, and critical care; the council on clinical cardiology; and the stroke council. Circulation. 2008;118(23):2452-83.

2. Joannidis M, Gstraunthaler G, Pfaller W. Xanthine oxidase: evidence against a causative role in renal reperfusion injury. Am J Phys. 1990;258(2 Pt 2):F232-6.

3. Joannidis M, Bonn G, Pfaller W. Lipid peroxidation-an initial event in experimental acute renal failure. Ren Physiol Biochem. 1989;12(1):47-55.

4. Patschan D, Patschan S, Muller GA. Inflammation and microvasculopathy in renal ischemia reperfusion injury. J Transp Secur. 2012;2012:764154.

5. Singbartl $K$, Joannidis M. Short-term effects of acute kidney injury. Crit Care Clin. 2015;31(4):751-62.

6. Chua HR, Glassford N, Bellomo R. Acute kidney injury after cardiac arrest. Resuscitation. 2012;83(6):721-7.

7. Geri G, Guillemet L, Dumas F, Charpentier J, Antona M, Lemiale V, Bougouin W, Lamhaut L, Mira JP, Vinsonneau C, et al. Acute kidney injury after out-ofhospital cardiac arrest: risk factors and prognosis in a large cohort. Intensive Care Med. 2015;41(7):1273-80.

8. Holzer M, Bernard SA, Hachimi-ldrissi S, Roine RO, Sterz F, Mullner M. Hypothermia for neuroprotection after cardiac arrest: systematic review and individual patient data meta-analysis. Crit Care Med. 2005;33(2):414-8.

9. Nielsen N, Wetterslev J, Cronberg T, Erlinge D, Gasche Y, Hassager C, Horn J, Hovdenes J, Kjaergaard J, Kuiper M, et al. Targeted temperature management at 33 degrees $C$ versus 36 degrees $C$ after cardiac arrest. N Engl J Med. 2013;369(23):2197-206.

10. Holzer M. Targeted temperature management for comatose survivors of cardiac arrest. N Engl J Med. 2010;363(13):1256-64.

11. Deakin CD, Nolan JP, Soar J, Sunde K, Koster RW, Smith GB, Perkins GD. European Resuscitation Council Guidelines for Resuscitation 2010 Section 4. Adult advanced life support. Resuscitation. 2010;81(10):1305-52.

12. Kellum JA, Lameire N. Diagnosis, evaluation, and management of acute kidney injury: a KDIGO summary (part 1). Crit Care. 2013;17(1):204.

13. Venkataraman R, Kellum JA. Defining acute renal failure: the RIFLE criteria, J Intensive Care Med. 2007;22(4):187-93.

14. De Rosa S, Samoni S, Ronco C. Creatinine-based definitions: from baseline creatinine to serum creatinine adjustment in intensive care. Crit Care. 2016;20:69.

15. Bottiger BW, Motsch J, Braun V, Martin E, Kirschfink M. Marked activation of complement and leukocytes and an increase in the concentrations of soluble endothelial adhesion molecules during cardiopulmonary resuscitation and early reperfusion after cardiac arrest in humans. Crit Care Med. 2002;30(11):2473-80.

16. Mattana J, Singhal PC. Prevalence and determinants of acute renal failure following cardiopulmonary resuscitation. Arch Intern Med. 1993;153(2):235-9.

17. Antunes PE, Prieto D, Ferrao de Oliveira J, Antunes MJ. Renal dysfunction after myocardial revascularization. Eur J Cardiothorac Surg. 2004;25(4):597-604.

18. Moore EM, Nichol AD, Bernard SA, Bellomo R. Therapeutic hypothermia: benefits, mechanisms and potential clinical applications in neurological, cardiac and kidney injury. Injury. 2011;42(9):843-54.

19. Susantitaphong P, Alfayez M, Cohen-Bucay A, Balk EM, Jaber BL. Therapeutic hypothermia and prevention of acute kidney injury: a meta-analysis of randomized controlled trials. Resuscitation. 2012;83(2):159-67.

20. Pelkey TJ, Frank RS, Stanley JJ, Frank TS, Zelenock GB, D'Alecy LG. Minimal physiologic temperature variations during renal ischemia alter functional and morphologic outcome. J Vasc Surg. 1992;15(4):619-25.

21. De Rosa S, Antonelli M, Ronco C. Hypothermia and kidney: a focus on ischaemia-reperfusion injury. Nephrol Dial Transplant. 2017;32(2):241-47.

22. Delbridge MS, Shrestha BM, Raftery AT, El Nahas AM, Haylor JL. The effect of body temperature in a rat model of renal ischemia-reperfusion injury. Transplant Proc. 2007;39(10):2983-5.

23. Raper JD, Wang HE. Urine output changes during Postcardiac arrest therapeutic hypothermia. Ther Hypothermia Temp Manag. 2013;3(4):173-7.

24. Badjatia N. Hyperthermia and fever control in brain injury. Crit Care Med. 2009;37(7 Suppl):S250-7.

25. Scholefield BR, Duncan HP, Morris KP. Survey of the use of therapeutic hypothermia post cardiac arrest. Arch Dis Child. 2010;95(10):796-9.

26. Tveita T. Rewarming from hypothermia. Newer aspects on the pathophysiology of rewarming shock. Int J Circumpolar Health. 2000;59(3-4):260-6.

27. Bouwes A, Robillard LB, Binnekade JM, de Pont AC, Wieske L, Hartog AW, Schultz MJ, Horn J. The influence of rewarming after therapeutic hypothermia on outcome after cardiac arrest. Resuscitation. 2012;83(8):996-1000.

28. Polderman $\mathrm{KH}$, Herold I. Therapeutic hypothermia and controlled normothermia in the intensive care unit: practical considerations, side effects, and cooling methods. Crit Care Med. 2009;37(3):1101-20.

29. Fries M, Stoppe C, Brucken D, Rossaint R, Kuhlen R. Influence of mild therapeutic hypothermia on the inflammatory response after successful resuscitation from cardiac arrest. J Crit Care. 2009;24(3):453-7.

30. Yano T, Nozaki Y, Kinoshita K, Hino S, Hirooka Y, Niki K, Shimazu H, Kishimoto K, Funauch M, Matsumura I. The pathological role of IL-18Ralpha in renal ischemia/reperfusion injury. Lab Invest. 2015;95(1):78-91.

31. Dinarello CA, Novick D, Kim S, Kaplanski G. Interleukin-18 and IL-18 binding protein. Front Immunol. 2013;4:289.

32. Ren H, Zhou X, Dai D, Liu X, Wang L, Zhou Y, Luo X, Cai Q. Assessment of urinary kidney injury molecule-1 and interleukin-18 in the early post-burn period to predict acute kidney injury for various degrees of burn injury. BMC Nephrol. 2015;16:142.

33. Nisula S, Yang R, Poukkanen M, Vaara ST, Kaukonen KM, Tallgren M, Haapio M, Tenhunen J, Korhonen AM, Pettila V. Predictive value of urine interleukin18 in the evolution and outcome of acute kidney injury in critically ill adult patients. Br J Anaesth. 2015;114(3):460-8.

34. Lin $X$, Yuan J, Zhao $Y$, Zha $Y$. Urine interleukin-18 in prediction of acute kidney injury: a systemic review and meta-analysis. J Nephrol. 2015;28(1):7-16. 